\title{
MODERN TELECOMMUNICATION NETWORKS IN THE AERONAUTICAL TELECOMMUNICATION NETWORK (ATN)
}

\author{
A. Novák \\ University of Žilina, Department of Air Transport, Univerzitna 1, 01026 Žilina, Slovakia \\ E-mail: Andrej.Novak@fpedas.utc.sk \\ Received 2005-09-22, accepted 2006-12-11
}

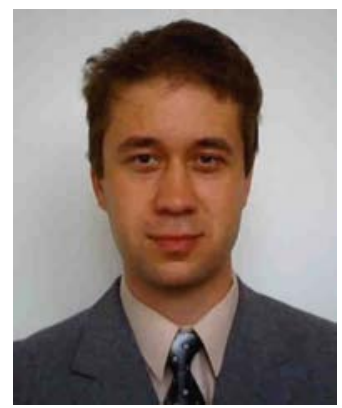

Andrej NOVAK, PhD. is a member of the staff of the Department of Air transport, Faculty of Operations and Economics of Transport and Communications at the University of Žilina. In 1998 he earned a Master's Degree in Radio Communications Technology from the Faculty of Electrical Engineering at the University of Žilina (Slovakia). Major fields of interest are: CNS/ATM, Transport and Traffic System Analysis.

\begin{abstract}
This paper summarizes the results of a study of modern telecommunication technology in the Aeronautical Telecommunication Network. The ATN is a data communications inter-network that provides its users a robust and reliable Air/Ground and Ground/Ground communications service. The Air Telecommunication Network is build on a ring of fixed telecommunication networks. The article deals with the integration of modern telecommunication technology into the still developing sector of aeronautical telecommunication.
\end{abstract}

Keywords: Aeronautical Telecommunication Network, air traffic management, data-link.

\section{Introduction}

To face the liberalization of air traffic in the world and to adapt their services to the demand, airlines have multiplied the number of flights and use smaller aircraft. This concentration of air traffic with respect to time is worsened by a simultaneous increase in concentration with respect to space due to the strategy of airlines of adopting hubs as cornerstones of their network of operations. This situation has led to a significant increase in the workload of air traffic controllers, which in turn imposes constraints and delays on air traffic in order to keep meeting the high safety standards of this domain.

A limit to the capacity of the sector today is very often the radiotelephony workload of the executive controller. Air ground data link can reduce the controller's and the pilot's workload through a decrease in radiotelephony workload. Data link communications will increase controller efficiency and will reduce voice congestion. These benefits will offer reductions in controller and pilot workload and, consequently, provide an opportunity to increase airspace capacity. The availability of a second communication channel will reduce communication errors and the lassitude of aircrew and controllers, therefore contributing to higher safety levels. Radio communications have a number of drawbacks in today's busy traffic environment. Pilots have to listen to each controller-initiated communication while approximately only one in twenty communications is addressed to the flight in question. This leads to crew fatigue. Blocking of frequencies by simultaneous transmissions and stuck microphone buttons are a common occurrence. A reduction of the pilot's communication workload will allow concentrating on other tasks and thus contributing to higher safety levels.

The Aeronautical Telecommunication Network (ATN) is one of the main cornerstones of the integration of data-link within the ICAO CNS/ATM concept. It has been designed to allow seamless data communications all over the world among air traffic management organizations, airlines, and aircraft, in order for these three parties to better coordinate their actions. When flying over areas with high traffic densities like European airspace, the ATN will allow intensive reliable data communications between airborne and ground computers. This is expected to reduce the workload and misunderstandings of pilots and controllers, and increase automation while maintaining safety, thereby contributing to the alleviation of current problems. In 
addition, the ATN will allow enhanced data communications between airlines and the ATM Organizations (ATSOs), providing an improved means of coordination for seamless, more effective operations [1].

\section{The European ATN Programme}

Europe is contributing much to the development of the ATN. This is being achieved by participating in standartizing the system and validating the technical and operational and by preparing implementation plans. A large effort to certify the system has also started recently. All actors in the ATS arena, the Commission of the European Community (CEC), EUROCONTROL, European ATSOs, airlines, equipment manufacturers, and communication service providers are involved in that process.

\subsection{Standards}

Europe has been instrumental in the adoption of ATN standards by ICAO in 1998 as part of the CNS/ATM-1 standards. This package includes standards for the network aspects of ATN and for ATN applications (see Fig.1). So far, the following end-user applications have been standardized:

- Controller-Pilot Data-link Communications (CPDLC)

- Automatic Dependant Surveillance (ADS)

- Flight Information Service (ATIS)

- Aeronautical Message Handling Service (AMHS)

- ATS Interfacilities Data Communications (AIDC)

\subsection{Technical validation}

The technical validation of ATN standards started in Europe as early as 1992 (with initial prototyping activities like EURATN or TAR/TSS) and has been continually pursued since, to allow tracking of the changes in ICAO draft standards and to investigate deeper and deeper all aspects of ATN implementation. Prototyping of a large ATN network and of its applications has been successfully achieved through the ADS-Europe, ProATN and EOLIA programmes, including ground and airborne components of the system. Such prototype networks are now being linked to similar networks being developed in other parts of the world (USA, Asia-Pacific), therefore providing the worldwide trial platform that is needed to fully validate the ATN. Areas like network management, for which much remains to be done, have progressed in the EUROCONTROL ATIF/NMC project and in ProATN. The dimensioning and performance aspects of the system, for which it is necessary to have access to a large number of systems, are being handled through computer simulation work. All this represents a comprehensive programme that is well advanced but needs further work [3].

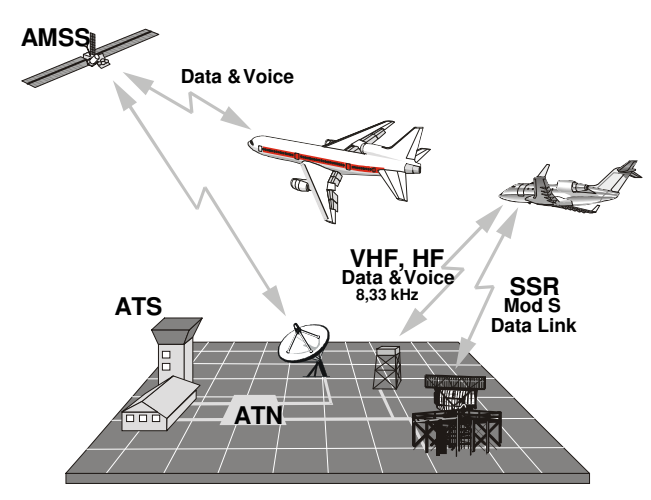

Fig 1. CNS/ATM communications over ATN

\subsection{Operational validation}

The technical validation of the system, although not fully completed, is now sufficiently advanced to allow operational validation to start. Operational requirements for ATN have been thoroughly defined within the ODIAC European framework. The new major European initiative in the area of pre-operational trials for ATN is the PETAL II programme. In this programme, the EUROCONTROL Maastricht air traffic control center (ATCC) is being fitted with ATN systems to support CPDLC pre-operational trials. At a later stage, the French Reims ATCC will join the programme, and it is anticipated that UK NATS and the German DFS will also join. UK NATS is already looking at implementing the ATN, along with FANS-1/A, to support aircraft operations in the North Atlantic. American Airlines is committed to equip four Boeing 767s with ATN avionics to support the PETAL II trials. The PETAL II preoperational trials started in the mid-2001. As importantly, the PETAL II trials are fully coordinated with the FAA CPDLC 1 programme, which provided a fully operational ATN/CPDLC capability in the Miami ATCC as early as beginning in June 2002 and was followed by a national deployment in the USA within the following year. In parallel with PETAL II, the Norwegian CAA (NCAA) has deployed a fully operational ATN network, using INMARSAT data-3 service, to provide flight and search and rescue information to helicopters operating in the North Sea airspace. Already more than 30 helicopters have been fitted with ATN/SATCOM avionics and are tracked in real-time using ADS by NCAA.

\section{Implementation plans}

\subsection{European states}

Work on ATN implementation plans for Europe has already started. Many studies led by the CEC and/or EUROCONTROL have initiated this work. They address all aspects of actual implementation, including initial cost-benefit analysis. This is the case of the CEC's ACCESS study, which is complemented by the work of 
the EUROCONTROL ATN Implementation Task Force. With a target of actual implementation of ATN in Europe for 2006, characterization work on the practical, coordinated implementation of ATN has to more forward quickly, and European ATSOs and airlines have to commit to such a plan for progress to be made. The Link 2000+ Programme, currently under characterization within EUROCONTROL, is a key towards such progress. The objective of the Link 2000+ Programme is to plan and co-ordinate the implementation of operational air/ground data link services for Air Traffic Management (ATM) in the core area of Europe in 2000-2007. In September and October 2000, the Chief Executive Standing Conference, a body comprising chief executives of all EUROCONTROL member states, endorsed by both the EUROCONTROL ATM/CNS CONSULTANCY GROUP and the LINK 2000+ Draft Master Plan. This has effectively launched this data-link implementation programme for Europe. At present, the area of LINK 2000+ implementation is constituted by the airspace of the following States: Austria, Belgium, Cyprus, the Czech Republic, France, Germany, Ireland, Italy, Portugal, the Netherlands, Romania, Spain, Sweden, Switzerland, Slovakia and the United Kingdom. The LINK 2000+ programme is closely coordinated with the US FAA CPDLC-1A/2 programmes, bringing equivalent data-link services into operation over the en-route US airspace and maximizing the benefits of data-link services for international airlines.

\subsection{Asia and Pacific states}

The work on ATN implementation plans for Asia and Pacific states has already started. The meeting of the ATN Transition Task Force Working Group held in Bangkok in September 2004 recognized the need to develop a strategy for implementation of the ground-toground ATN in the ASIA/PAC region in order to provide guidance to states to proceed with implementation activities according to the agreed strategy.

\section{Certification}

It must be done with a technology like ATN certification on an end-to-end basis, and it is no more an aircraft-only problem. This is now fully recognized, and both EUROCAE and RTCA are addressing this point. Tools to facilitate certification of systems are also under development. In Europe, EUROCONTROL is very actively working on the definition of a certification framework for data-link, to be used in particular for LINK 2000+. The development of qualification/certification tools such as the CTS (Conformance Testing Tool) or the CAERAF (Common American European Reference ATN Facility) is also under way to contribute to this effort.

\section{Technology}

\subsection{Equipment manufacturers}

The development of ATN technology is well advanced in Europe. On the side of ground systems, ATC manufacturers are already proposing ATN routers and portable software and have initiated the process of integration of data-link into their ATCC products. On the side of airborne systems, EADS is developing a new set of equipment to support ATM data-link on board aircraft. Prototypes of ATS Units (ATSUs) and Data-link Cockpit Display Units (DCDU) are already available for trials purposes. Certified portable ATN software is also being developed by European companies in cooperation with US companies and was integrated into airborne communication equipment in 2001.

\subsection{Communication service providers}

Both ARINC and SITA are committed to deploy VDL Mode 2 networks in Europe. This deployment will be ATN compliant, therefore ensuring a smooth transition path to ATN. An INMARSAT Data-3 mobile satellite service has been available for some time already and has been widely exercised with experimental ATN facilities (ADS-Europe). Such means are likely to constitute the second main Sub Network to support the ATN in Europe, as a backup to VDL Mode-2 [2].

\section{Conclusion}

The momentum for implementation of the ATN in the World and Europe is continuing to grow. There is increasing recognition that the ATN is an essential component of the future system, and that it will largely contribute to the resolution of the current capacity problems. The technical validation of the ATN technology and of its early applications is well advanced. Preoperational trials, involving actual controllers and pilots, are being put in place in their normal operating environments. Certification and human factors issues will likely be greatly progressed via such trials. In the past year, European ATSOs have provided their initial commitment to the LINK 2000+ Programme, aiming at implementing operational ATS data-link services based on ATN and VDL Mode-2, over Europe by 2006. Along with the launching of the equivalent US CPDLC programme, these constitute a major event for introduction of ATN-based data-link services for the ATM. The development of ATN products is well advanced to support such effort.

\section{Acknowledgments}

This research has been supported by the Scientific Grant Agency of the Ministry of Education of Slovak Republic and the Slovak Academy of Sciences (No: 1/2151/05). 


\section{References}

1. BRANGIER, F. The ATN situation in Europe. In Business Briefing: Global Civil Aviation \& Airport Development. London: World Market Research Centre, Nov. 2000, p. 45-58.

2. NOVAK A.; BUGAJ, M. Perspectives for satellite CSN. Studies of Faculty of operation and economics of transport and communications of University of Žilina, 2003, vol 19, p. 158-165.

3. STRENITZEROVA, M. New trends of strategic management. TRANSCOM 2005 University of Žilina, 2005, ISBN 80-8070-414-7, p. 159-163. 